\title{
Seroprevalence of Hepatitis $B$ and $C$ in the Western Brazilian Amazon Region (Rio Branco, Acre): A Pilot Study Carried Out During a Hepatitis B Vaccination Program
}

\author{
J. Tavares-Neto ${ }^{1,2}$, D. Almeida ${ }^{1}$, M. C. Soares ${ }^{3}$, \\ R. Uchoa ${ }^{2}$, S. Viana ${ }^{2}$, R. Darub ${ }^{2}$, E. Farias ${ }^{2}$, \\ G. Rocha ${ }^{2}$ L. Vitvitski ${ }^{4}$ and R. Paraná ${ }^{1}$
}

\author{
Postgraduate Program, University of Bahia, Brazil, \\ Group for the Study of Viral Hepatitis, Salvador, $B A^{1}$; \\ Acre State Public Health Program ${ }^{2}$, Rio Branco, AC; \\ Evandro Chagas Institute ${ }^{3}$, Belém, PA, Brazil; INSERM, \\ 271 Unit $^{4}$, Lyon, France
}

In 1999, on the occasion of the application of the first vaccine dose during the state vaccination campaign against hepatitis $B$ virus (HBV), 390 individuals from the town of Rio Branco, Acre, aged two or more years were selected for the determination of the seroprevalence of $\mathrm{HBV}$ and HCV. HBV markers (HBsAg, anti-HBs, and anti-HBc IgG) were determined on this occasion and anti-HBs antibodies were also assessed 30 days after the third vaccine dose. At the time of vaccination, $39 \%$ of the individuals were still susceptible to $\mathrm{HBV}$, while $61 \%$ presented serologic evidence of previous HBV contact or previous vaccination. The individuals with previous HBV contact were significantly older $(p<0.001)$ than those without $\mathrm{HBV}$ markers. Of the 192 individuals who returned for reexamination, 30 days after the third dose, $158(82.3 \%)$ had received three vaccine doses, and only $60(31.2 \%)$ belonged to the group without $\mathrm{HBV}$ markers. In these individuals, the seroconversion rate after the third dose was $92 \%(55 / 60)$. In conclusion, we found considerable $\mathrm{HBV}$ in this population, indicating the need for pursuing the immunization programs. We also found high rates of vaccination coverage in the Western Brazilian Amazon region.

Key Words: Hepatitis B vaccination, Amazonia, hepatitis B, hepatitis C, epidemiology.

Hepatitis B is a worldwide public health problem, especially in developing countries. Chronic infection after exposure to hepatitis B virus (HBV) has been observed in $30 \%$ to $90 \%$ of children aged less than five years. On the other hand, exposed adults become chronic carriers of HBV in only 2 to $5 \%$ of cases [1]. In the United States, it is estimated that 500,000 to $1,000,000$ individuals are chronically infected with the B virus, and $15 \%$ to $25 \%$ of them will die prematurely due to liver disease or hepatocellular carcinoma [2]. These aspects

Received on 17 August 2003; revised 22 January 2004.

Address for correspondence: Dr. Raymundo Paraná. Av. Juracy Magalhaes Jr. 2096, Sala 510, Salvador-Bahia, Brazil,Zip code: 41920-000. E-mail: rparana@ufba.br Phone: (5571)350-4651.Fax: (5571)353-4980.

The Brazilian Journal of Infectious Diseases 2004;8(2):133-139 (C) 2004 by The Brazilian Journal of Infectious Diseases and Contexto Publishing. All rights reserved. of the natural history of HBV have prompted the implementation of vaccination programs against $\mathrm{HBV}$ in various countries worldwide [3-5].

In the Brazilian Amazon region, $\mathrm{HBV}$ infection is a severe health problem, which is complicated by the presence of hepatitis D virus (HDV) in the area. Fulminant hepatitis outbreaks due to HDV superinfection of HBV carriers is still frequently observed in this region [6]. No recent seroepidemiologic studies on HBV are available in the state of Acre, in the eastern Brazilian Amazon region, although evidence obtained from hospital reports and blood donor candidates indicates a high prevalence of individuals chronically infected with HBV. Most of them are adolescents or young adults, though older adults commonly suffer from acute hepatitis B.

Unfortunately, no population study concerning the prevalence of $\mathrm{HCV}$ is available so far. The large number 
of HCV carriers in our outpatient unit seen at the referral hospital of Rio Branco (Acre) means that further prevalence studies are warranted.

The first-generation plasma-derived vaccine against the B virus was introduced in the 1970's [7]. In the 1980's, a recombinant HBsAg vaccine was produced, which showed excellent tolerance and efficacy [8-11].

In Brazil, the official immunization schedule includes the HBV vaccine, only for newborns and children younger than 15 years. Despite this recommendation, HBV vaccine coverage of newborns was less than $25 \%$ during the period from 1990 to 1998 in all 22 municipalities of the state of Acre (DABS SESSACRE, unpublished data). This situation led the government of Acre, supported by the National Health Foundation and the National Immunization Program (PNI, Ministry of Health), to organize a mass vaccination campaign against $\mathrm{HBV}$ in 1996, which consisted of the application of three doses (at 0,1 and 6 months).

Taking advantage of this ambitious vaccination program, we have studied serum $\mathrm{HBV}$ and $\mathrm{HCV}$ markers in a subset of vaccinated individuals from the town of Rio Branco, Acre, obtained before application of the first $\mathrm{HBV}$ vaccine dose and reexamined in part of the sample 30 days after the third dose.

\section{Material and Methods}

On the first day of the state vaccination campaign against $\mathrm{HBV}$, seven mobile teams (each consisting of a medical student and a technician from the Central Public Health Laboratory of Acre) visited the 212 vaccination centers of the town of Rio Branco. Each team was responsible for one of the two district areas of the municipality of Rio Branco, an urban area with about 280,000 inhabitants. Rio Branco is the westernmost town among the large cities of the Brazilian Amazon region (Figure 1).

Upon the arrival of the mobile team at a given vaccination center, one or two individuals were selected for blood collection, answered a questionnaire and gave written informed consent to participate in the study.
The first individual selected was the person in the vaccination line who, upon arrival of the team, was seen by one of the volunteers ("vaccinator") of the respective center who recorded the personal data of each patient. At centers with more than 30 individuals per line, a second individual was selected, who was the person following the first one, provided that no family relationship existed between them. When one of these two persons refused to participate, the following person in the vaccination line was included. All infants aged less than 24 months were excluded due to difficulties in blood sample collection. A total of 394 individuals aged 2 to 79 years were evaluated.

The number of household dwellers and the number of rooms in the dwelling were obtained from the individuals included in the study (or their legally responsible guardian) as socioeconomic indicators. Patients reporting more than two individuals per room were considered to belong to a poor socioeconomic stratum, while two or fewer persons per room indicated a good socioeconomic level.

After filling out the questionnaire, $5 \mathrm{ml}$ venous blood was collected without anticoagulant. The blood samples were then centrifuged and stored at $-20^{\circ} \mathrm{C}$ at the Central Public Network Laboratory until they were sent to the Hepatitis Laboratory, Evandro Chagas Institute, Belém, Brazil, for the determination of serologic markers of HBV (HBsAg, anti-HBs and total anti-HBc IgG), $\mathrm{HCV}$, and HDV. All markers were assayed using a commercial enzyme immunoassay (Organon ${ }^{\circledR}$, Abbott, Chicago, IL, for HBsAg and anti-HDV; anti-HBs, anti$\mathrm{HBc} \mathrm{IgG}$, and anti-HCV).

The second phase of the study was carried out one month after application of the third $\mathrm{HBV}$ vaccine dose between January 19 and January 21, 2000 (at this time, the serological results of the first serum samples were still unknown). Eight days before the beginning of the second phase all participants in the study $(n=394)$ received a letter from the State Secretary Office of Health and Sanitation (SESSACRE), inviting them for a new blood collection for serological determination of anti-HBs markers. The reason for the study was explained in simple language accessible to the lay public. One hundred ninety two (49.2\%) individuals accepted 
Figure 1. Location of the State of Acre in the Amazon region

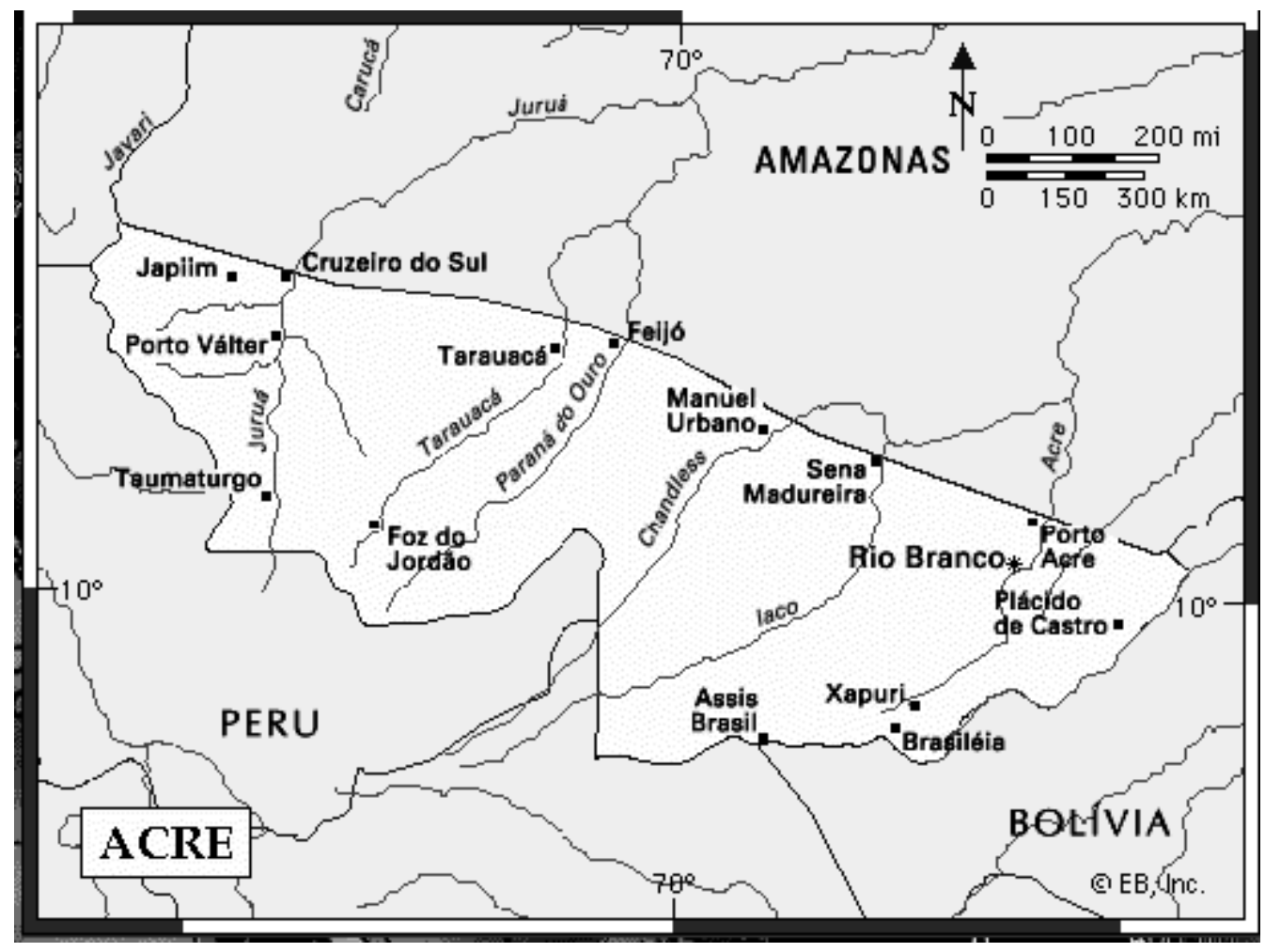

the invitation during the second phase and attended the Blood Center of Acre State (HEMOACRE). The blood samples obtained were then processed as described above, and the second module of the questionnaire was filled out.

The vaccine used during the state vaccination campaign against $\mathrm{HBV}$ was Engerix ${ }^{\circledR} \mathrm{B}$ (SmithKline Beecham). The vaccine dose used was $10 \mu \mathrm{g}$ for children aged 2 to 10 years and $20 \mu \mathrm{g}$ for individuals 11 years or older.

Statistical analysis was carried out using the Statistical Package for the Social Sciences (SPSS) software. Natives from the state of Acre and individuals born in the municipalities of the eastern region of the state were recorded as being from the Vale do Rio Branco region, while those born in municipalities of the central and western region were considered to be from Vale do Rio Juruá. The mean, standard deviation and median were determined for continuous variables, while frequencies were assessed for categorical variables. The student's t test was used to analyse continuous variables and the $X^{2}$ test was performed to analyse categorical variables. The associations were considered to be statistically significant at an a error probability of $\leq 0.05(\leq 5 \%)$.

\section{Results}

First phase of the study

Of the 394 individuals selected, four were excluded because of insufficient serum samples. The gender proportion was similar in this population ( $\mathrm{n}=390$; male: $48.2 \%$ vs. female: $51.2 \%$ ), and mean age was $26.5 \pm$ 14.9 years (median of 23 and mode of 13 years), range 2 to 79 years. The distribution of individuals according to positivity for the HBV serologic markers studied was 
Table 1. Characteristics of the population from the Rio Branco municipality (Acre) according to hepatitis B virus (HBV) serologic group

\begin{tabular}{|c|c|c|c|c|c|}
\hline \multicolumn{6}{|c|}{ Serologic group, n (\%) } \\
\hline Variable & $\begin{array}{c}\text { Total } \\
(n=390)\end{array}$ & $\begin{array}{l}\text { HBV carrier } \\
\quad(n=13)^{\mathrm{a}}\end{array}$ & $\begin{array}{c}\text { Immune } \\
(\mathrm{n}=81)^{b}\end{array}$ & $\begin{array}{l}\text { Old inf. } \\
(n=144)^{c}\end{array}$ & $\begin{array}{l}\text { Susceptible } \\
\qquad(\mathrm{n}=152)^{d}\end{array}$ \\
\hline \multicolumn{6}{|l|}{ Gender } \\
\hline Female & $202(51.8)$ & $6(46.2)$ & $43(53.1)$ & $71(49.3)$ & $82(54.0)$ \\
\hline Male & $188(48.2)$ & $7(53.8)$ & 38 (46.9) & $73(50.7)$ & $70(46.0)$ \\
\hline \multicolumn{6}{|l|}{ Age (years) } \\
\hline Mean & 26.5 & 35.7 & 15.4 & 36.7 & 21.9 \\
\hline$\pm \mathrm{SD}$ & 14.9 & 13.2 & 9.9 & 14.1 & 11.2 \\
\hline \multicolumn{6}{|l|}{ Racial group } \\
\hline Caucasian & $183(46.9)$ & $7(53.8)$ & $36(44.4)$ & $70(48.6)$ & $70(46.0)$ \\
\hline Non-Caucasian & $207(53.1)$ & $6(46.2)$ & $45(55.6)$ & $74(51.4)$ & $82(54.0)$ \\
\hline \multicolumn{6}{|l|}{ Origin } \\
\hline Acre & $316(81.0)$ & $10(76.9)$ & $71(87.6)$ & 115 (79.9) & $120(79.0)$ \\
\hline Other states & $74(19.0)$ & $3(23.1)$ & $10(12.4)$ & $29(20.1)$ & $32(21.0)$ \\
\hline \multicolumn{6}{|l|}{ Acre region $^{\mathrm{e}}$} \\
\hline Rio Acre & $257(81.3)$ & $7(70.0)$ & $68(95.8)$ & $75(65.2)$ & $107(89.2)$ \\
\hline Rio Juruá & $59(18.7)$ & $3(30.0)$ & $3(4.2)$ & $40(34.8)$ & $13(10.8)$ \\
\hline \multicolumn{6}{|c|}{ History of vaccination } \\
\hline No & $291(74.6)$ & $8(61.5)$ & $43(53.1)$ & $109(75.7)$ & $131(86.2)$ \\
\hline Yes & $99(25.4)$ & $5(38.5)$ & $38(46.9)$ & $35(24.3)$ & $21(13.8)$ \\
\hline \multicolumn{6}{|l|}{ History of hepatitis } \\
\hline No & $337(86.4)$ & $9(69.2)$ & $71(87.6)$ & $127(88.2)$ & $130(85.5)$ \\
\hline Yes & $53(13.6)$ & $4(30.8)$ & $10(12.3)$ & 17 (11.8) & $22(14.5)$ \\
\hline
\end{tabular}

(a) HBV carrier (HBsAg positive and anti-HBc positive); (b) Vaccinated or immune (anti-HBs positive and negative for the other markers); (c) Past infection (anti-HBc positive, HbsAg negative and anti-HBs positive or negative); (d) Susceptible (negative for all three markers); (e) Including 316 individuals from the Vale do Rio Acre and Vale do Rio Juruá regions.

as follows: $3.3 \%(\mathrm{n}=13)$ were positive for $\mathrm{HbsAg}$ and $34.3 \%(n=134)$ for anti-HBs and anti-HBc IgG. Anti-HBc IgG alone was detected in $13(3.3 \%)$ individuals. Anti-HBs alone (previous vaccination) were observed in $14.1 \%(n=55)$ of the individuals. Only $39.0 \%(n=152)$ of the population studied was seronegative for all three HBV serologic markers (HBsAg, anti-HBc and anti-HBs). Table I shows the distribution of the serologic groups, i.e., previously vaccinated, previous HBV exposure, and two patients with HDV co-infection.
Of 386 (99.0\%) individuals studied, 16 (4.2\%) were positive for anti-HCV, but no confirmatory test was applied.Table 1 also shows the demographic characteristics of the sample, with a similar gender distribution $(\mathrm{p}>0.48)$ being observed for each serological group. Mean age was significantly higher in the $\mathrm{HBsAg}$-positive group (35.7 \pm 13.2 years) and in the group with $\mathrm{HBV}$ exposure. (36.7 \pm 14.1 years; $p<0.03$ and $p<0.001$, respectively) and was significantly lower in the groups of previously vaccinated individuals (15.4 \pm 9.9 years) and individuals without HBV markers $(21.9 \pm 11.2$ years; $\mathrm{p}<0.0001)$. 
Race distribution $($ whites $=183$, non- whites $=207$; p>0.59) and origin (born in the state of Acre vs. born in other states; $p>0.39$ ) were similar among the serological groups. When individuals from the state of Acre $(n=316,81.0 \%)$ were analyzed according to the region of the municipality where they were born (Vale do Rio Acre or Vale do Rio Juruá), individuals from the towns of Vale do Rio Juruá were significantly more frequent in the group with a past infection $(\mathrm{p}<0.001)$ and less frequent in the group of vaccinated $(p<0.001)$ or susceptible individuals ( $\mathrm{p}<0.006)$.

A strong association with previous immunization $(p<0.001)$ was observed in individuals positive for antiHBs, without anti-HBc IgG $(\mathrm{p}<0.001$, Table 1). However, a similar distribution of the vaccination history was observed for HbsAg-positive individuals ( $p>0.20$ ), and in those with a past and resolved infection $(p=0.69)$. The history of jaundice was similar for the serological groups studied (HBsAg, $\mathrm{p}>0.08$; anti-HBs positive with and without anti-HBc IgG, p>0.70; individuals without $\mathrm{HBV}$ markers, $\mathrm{p}>0.70$ ).

In the analysis of the distribution of individuals according to the number of rooms in the dwelling, most of them $(64.9 \%, 253 / 390)$ belonged to the stratum of $\leq 2$ persons/room, while the distribution of those with more than two persons/room was similar for the serological groups.

\section{Second phase of the study}

Only 192 (49.2\%) of the 394 invited individuals participated in the second phase of the study, with return of the letters to the sender (SESSACRE). The main reason $(108 / 198,54.5 \%)$ for the lack of participation was related to mail and address changes.

Among the 192 individuals analyzed, $158(82.3 \%)$ reported the use of three HBV vaccine doses, 28 $(14.6 \%)$ received two doses and $6(3.1 \%)$ only one dose on the occasion of the state vaccination campaign against HBV. Forty-five $(23.4 \%)$ of them were previously immune (anti-HBs positive, detected on the occasion of the administration of the first vaccine dose), $8(4.2 \%)$ were HBV carriers (HbsAg positive), and $79(41.2 \%)$ presented a serology compatible with a past and resolved HBV infection, i.e., only 60 (31.2\%) individuals were still susceptible to HBV (HBsAg, antiHBs and anti-HBc negative).

Among the 60 individuals susceptible to $\mathrm{HBV}$, most $(n=50,83 \%)$ received three vaccine doses, $7(12 \%)$ received two doses, and $3(5 \%)$ only one dose, with the anti-HBs seroconversion rate (serum sample obtained 30 days after the third vaccine dose) being $92 \%$ (46/50), $100 \%$ (7/7) and 67\% (2/3), respectively.

Of the $5(8 \%)$ non-seroconverted cases (anti-HBs negative 30 days after the third vaccine dose), one had received only one dose and four had received three doses.

At the end of the study, the results of the serological tests (including those positive for anti-HCV) were sent to the 390 individuals by regular mail. When appropriate, the person was advised to attend the Service of Infectious and Parasitic Diseases of the General Hospital of Rio Branco. Community health agents from the area in question tried to identify cases of previously returned correspondence $(n=108)$ or those returned on the second occasion $(n=41)$, and were able to locate $136(91.3 \%)$ individuals.

\section{Discussion}

Second-generation vaccines using recombinant viral protein have provided efficient prophylaxis against $\mathrm{HBV}$, but despite these efforts about 350 million people are estimated to be infected with the virus, rendering HBV an important carcinogen [12]. Nevertheless, vaccines and other control measures have led to a decline in the prevalence of HBV over the last few years, although HBV infection continues to be a severe public health problem worldwide, with some regions such as Asia, the east coast of Africa and the Amazon region being hyperendemic [13]. Especially in this region of Latin America, vaccination against HBV can also lead to an associated decline in the prevalence of HDV.

In this population, although vaccination of children younger than 15 years, including newborns, has been encouraged by health authorities, only $25.4 \%$ of the 
individuals reported previous vaccination against $\mathrm{HBV}$, a rate similar to the vaccination frequencies reported for the 22 municipalities of the state of Acre during the period from 1990 to 1998 (DABS - SESSACRE, unpublished data).

The number of cases in the state of Acre with chronic viral hepatitis or cirrhosis, including patients younger than 25 years and individuals transferred for treatment outside the home (DCA - SESSACRE, unpublished data), demonstrates the relevance of $\mathrm{HBV}$ as a health problem, and also explains the great mobilization of the population on the days of state vaccination, as well as the high rates $(>82 \%)$ of vaccination coverage reached on the days of the state campaign (DABS/ PNI - SESSACRE, unpublished data).

As an example of the relevance of HBV infection in the state of Acre, even though acute hepatitis B caused jaundice in only one-third of the cases [14], a history of hepatitis was reported by $15.7 \%$ of the individuals studied. In contrast, a large part of the population tested positive for HBsAg (3.3\%) or for HBV serologic markers compatible with past exposure. Another group of individuals $(20.8 \%)$ presented isolated anti-HBs compatible with a history of vaccination, a frequency similar to that observed for individuals who reported previous vaccination $(25.4 \%)$. Only $39.0 \%$ of the vaccinated individuals were still susceptible to HBV infection (HBsAg, anti-HBs and anti-HBc negative) and thus benefitted from the vaccination program. Therefore, it is important that in this region vaccination against $\mathrm{HBV}$ is preceded by serum anti-HBs determination in isolated cases or in small population groups, an unfeasible and expensive step when applied to vaccination programs similar to that carried out in the state of Acre.

In addition, the rejection rate of blood donor candidates due to anti-HBc seropositivity has been found to be abnormally high in the Amazon region when compared to other regions of the country [15]. This is further demonstrated by the previous observation that $36.9 \%$ of individuals presented HBV markers.

Recently, further concern has been raised regarding the high prevalence of anti-HCV among blood donor candidates in this region. This fact, together with the exclusion of blood donors due to anti-HBc IgG seropositivity, has generated a serious shortage of blood in the region.

Despite the pilot study character of the present investigation, these indicators, in addition to the high prevalence of anti-HCV (4.2\%) and anti-HDV $(0.5 \%)$, demonstrate the relevance of hepatotropic viral infections in this region of the country [6] and should thus encourage further action by government and research institutions.

Unfortunately, no confirmatory test was performed in order to validate ELISA anti-HCV-positive cases. Nevertheless, we found a high prevalence of anti-HCV in this population, which seems to be very close to the actual prevalence of $\mathrm{HCV}$ in blood donor candidates from the state of Acre. In addition, the serum samples were handled under appropriate conditions and stored at $-20^{\circ} \mathrm{C}$, as soon as collected.

Although associated with or influenced by multiple biological, social and economic factors in Brazil, gender and race distribution was similar among the four serological groups, further supporting the assumption of homogeneity of the sample and the wide dissemination of $\mathrm{HBV}$ in the population, irrespective of other social and biological characteristics. In this respect, the similarity between the serological groups in the proportion of individuals living in dwellings with more than two persons/room also demonstrates that the circulation of $\mathrm{HBV}$ in the population from Rio Branco town seems to be independent of socioeconomic level.

No difference was observed between individuals born in the state of Acre and those from other states of the country, although this type of association is affected by multiple variables, including the time of residence in the Amazon region or, more specifically, in the state of Acre.

The impact of HBV infection has been known to be more relevant among residents in the Vale do Rio Juruá municipality (DABS - SESSACRE and HEMOACRE, unpublished data), in agreement with the significantly higher frequency $(67.8 \%, \mathrm{p}<0.001)$ of anti-HBc-positive cases among individuals from this area.

The high frequency (82.3\%) of individuals receiving three vaccine doses among those reassessed 30 days 
after the third dose demonstrates good compliance of the population with the state vaccination campaign.

Although one may speculate about the large number of individuals who did not respond to the call during the second phase, this apparently did not cause distortions in the results, since a similar distribution of the variables was observed for individuals who participated in the second phase of the study $(n=192)$ and those studied during the first phase $(n=390)$. The few nonseroconverted cases $(n=5)$, especially the four individuals who received three vaccine doses, might be explained by factors associated with vaccine application, the vaccine itself or host characteristics $[16,17]$.

In conclusion, evidence of the strong impact of HBV on public health demonstrates that a similar vaccination program could be applied in places with characteristics similar to those of Acre state, where large, geographically isolated areas prevent the implementation of various public programs or services. This study also demonstrated that HCV infection is an important problem in the Brazilian Amazon region, which requires further studies and greater attention on the part of federal government health authorities.

\section{Acknowledgments}

We thank the medical students of Acre and the students of the Medical School of Cuba, as well as Master's student Jailson de Araújo Silva(UFBA) and the students Juliano Freitas-Andrade (UFBA), Ciro Falcão Macedo Jr. (UNI - RJ), and Thiago Neves Paiva (UBM - RP, SP). This study was supported by SESSACRE (Government of Acre), CNPq, and the CAPES/COFECUB 404/02 project as part of the French/Brazilian Study Group on Viral Hepatitis.

\section{References}

1. Walsh K., Alexander G.J. Update on chronic viral hepatitis. Postgrad Med J 2001;77:498-505.

2. Holmes-Mc Nary M. Impact factors on development of cirrhosis and subsequent hepatocellular carcinoma. Compend Contin Educ Dent 2001;22,19-33.
3. Hsu H., Chen D., Chuang C., et al. Efficacy of a mass hepatitis B vaccination program in Taiwan. Studies on 3464 infants of hepatitis B surface antigen-carrier mothers. JAMA 1988;260:2231-5.

4. Goh K., Doraisingham S., Tan K., et al. The hepatitis B immunization programme in Singapore. Bulletin of the World Health Organization 1989;67:65-70.

5. Jilg W. Preventive vaccination for viral hepatitis. Zeitschrift für Gastroenterologie 1997;35:585-90.

6. Souto F., Fontes C., Oliveira J., et al. Epidemiological survey of infection with hepatitis B virus in the savanna and wetlands (Pantanal) of central Brazil. Annals of Tropical Medicine and Parasitology 1997;91:411-6.

7. Van Herck K., Van Damme P., Collard F., Thoelen S. Twodose combined vaccination against hepatitis A and B in healthy subjects aged 11-18 years. Scandinavian Journal of Gastroenterology 1999;34:1236-40.

8. Emini E.A., Ellis R.W., Miller W.J., et al. Production and immunological analysis of recombinant hepatitis B vaccine. Journal of Infection 1986;13(Suppl. A):3-9.

9. Zajac B.A., West D.J., McAleer W.J., Scolnick E.M. Overview of clinical studies with hepatitis vaccine made by recombinant DNA. Journal of Infection 1986;13(Suppl. A):36-45.

10. Jilg W., Schmidt M., DeinhardtF. Vaccination against hepatitis B: Comparison of three different vaccination schedules. The Journal of Infectious Diseases 1989; 160,766-9.

11. Hadler S.C., de Monzon M.A., Lugo D.R., Perez M. Effect of timing of hepatitis $\mathrm{B}$ vaccine doses on response to vaccine in Yucpa Indians. Vaccine 1989;7:106-10.

12. Chen C.J., You S.L., Lin L.H., et al. Cancer epidemiology and control in Taiwan: a brief review. Jpn J Clin Oncol 2002;32 (Suppl S):66-81.

13. Bensabath G., Hadler S.C., Soares M.C., et al. Hepatitis delta virus infection and Labrea hepatitis. Prevalence and role in fulminant hepatitis in the Amazon Basin. JAMA 1987; 258,479-83.

14. Silva L.C., CarrilhoF.J., Pietro A., et al. Epidemiological aspects of acute viral hepatitis in São Paulo, Brazil. Revista do Instituto de Medicina Tropical de São Paulo 1986;28,400-5.

15. Souto F., Fontes C., Gaspar A., et al. Concomitant high prevalence of hepatitis $\mathrm{C}$ virus antibody and hepatitis $B$ viral markers in a small village of the Amazon region in Mato Grosso State, Brazil. Revista do Instituto de Medicina Tropical de São Paulo 1996;38,221-3.

16. Liu P., Xu H., Wang X., et al. Field epidemiological and experimental study on relationship between genetic factor and nonresponse or hyporesponse to hepatitis B vaccine. Chin Med J 2000; 113,547-50.

17. Perera J., Perera B., Gamage S. Seroconversion after hepatitis $B$ vaccination in healthy young adults, and the effect of a booster dose. Ceylon Med J 2002;47:6-8. 